\title{
Hereditary motor and sensory neuropathy, Okinawa type
}

INSERM

\section{Source}

INSERM. (1999). Orphanet: an online rare disease and orphan drug data base. Hereditary motor and sensory neuropathy, Okinawa type. ORPHA:90117

Hereditary motor and sensory neuropathy, Okinawa type is a rare, genetic, axonal hereditary motor and sensory neuropathy characterized by the adult-onset of slowly progressive, symmetric, proximal dominant muscle weakness and atrophy, painful muscle cramps, fasciculations and distal sensory impairment, mostly (but not exclusively) in individuals (and their descendents) from the Okinawa region in Japan. Absent deep tendon reflexes, elevated creatine kinase levels and autosomal dominant inheritance are also characteristic. 